\title{
Refugees Connecting with a New Country through Community Food Gardening
}

\author{
Neil Harris ${ }^{1,2, \dagger, *}$, Fiona Rowe Minniss ${ }^{2, \dagger}$ and Shawn Somerset ${ }^{3, \dagger}$
}

1 Population and Social Health Research Program, Griffith Health Institute, Gold Coast Campus, Griffith University, Gold Coast, Queensland 4222, Australia

2 School of Medicine, Gold Coast Campus, Griffith University, Gold Coast, Queensland 4222, Australia; E-Mail: f.roweminniss@griffith.edu.au

3 School of Allied Health, Faculty of Health Sciences, Australian Catholic University, Brisbane, Queensland 4014, Australia; E-Mail: shawn.somerset@acu.edu.au

$\dagger$ These authors contributed equally to this work.

* Author to whom correspondence should be addressed; E-Mail: n.harris @ griffith.edu.au; Tel.: +61-7-555-27879; Fax: +61-7-555-28799.

Received: 11 June 2014; in revised form: 15 August 2014 / Accepted: 22 August 2014 / Published: 5 September 2014

\begin{abstract}
Refugees are a particularly vulnerable population who undergo nutrition transition as a result of forced migration. This paper explores how involvement in a community food garden supports African humanitarian migrant connectedness with their new country. A cross-sectional study of a purposive sample of African refugees participating in a campus-based community food garden was conducted. Semi-structured interviews were undertaken with twelve African humanitarian migrants who tended established garden plots within the garden. Interview data were thematically analysed revealing three factors which participants identified as important benefits in relation to community garden participation: land tenure, reconnecting with agri-culture, and community belonging. Community food gardens offer a tangible means for African refugees, and other vulnerable or marginalised populations, to build community and community connections. This is significant given the increasing recognition of the importance of social connectedness for wellbeing.
\end{abstract}

Keywords: refugee health; nutrition transition; community food garden; social connectedness 


\section{Introduction}

Populations that migrate from one country to another, in particular from a less industrialised to a highly industrialised country, undergo a consequent nutrition transition associated with changes in their physical and social environments, diet, physical activity, and access to healthcare $[1,2]$. Evidence suggests that on arrival migrants from developing countries typically have better overall health than the non-migrant population, often referred to as the "healthy migrant" paradox. It is paradoxical as, over time, migrant health status is prone to decline [3,4] as this population faces settlement difficulties associated with access to appropriate healthcare, language difficulties, financial difficulties as a result of unemployment, and cultural differences [5]. Influenced by such factors as low income, media and accessibility, food choices are a common cause of poor health among migrants, as they shift from a traditional "wholesome" diet, to a more refined, high caloric "western" diet [1]. Refugees are a particularly vulnerable category of such populations, whether moving from their traditional homelands to temporary refugee camps or settling in an industrialised host country.

The health of humanitarian migrants in Australia and other industrialised countries is relatively poor compared to sedentee populations [6-8]. African refugees comprise more than $30 \%$ of the Humanitarian Program annual intake in Australia [9]. African humanitarian refugees represent a relatively recent and growing sub-population in Australia with most migrating and settling in the past 15 years [10] as a result of conflicts arising from decolonisation and government instability [11]. Of the migrant sub-populations of Australia, the Sub-Saharan African community has the highest proportion of children aged 0-14 years (12\%) [12]. Most of the Sub-Saharan African refugee population identify as Christian, and are women with young children and families, with limited English and educational attainment [11]. Approximately 40\% of all Humanitarian Migrants living in Queensland reside in homes with between 5-7 people [13].

Many African humanitarian migrants have experienced serious human rights violations as a result of war and organised violence, as well as extended stays in refugee camps. As a result of their cultural transition and traumatic experiences, many African refugees suffer from significant social displacement, as well as psychological and physical health problems $[9,14]$. Compounding their social displacement and disconnection, many refugees come from farming backgrounds, and their forced migration to a "landless" urban environment presents additional challenges [15].

Renzaho and colleagues [15] noted a dual burden of overweight/obesity and under-nutrition in a group of refugee families from sub-Saharan Africa. Other studies, for example on Liberian, Somali and Vietnamese refugees at different locations, have reported on the difficulties these groups have in establishing healthy food habits upon settlement [16-18]. The food consumption habits adopted by such people upon settlement in Australia and other highly industrialised nations [19] are likely to intensify the consequences of their already compromised health status. The development of appropriate lifestyle and health interventions for refugee populations settling in Australia is a major challenge since access to and engagement with these populations is complicated by a range of cultural and social barriers [20]. Furthermore, while this population establishes early social connections within their own ethnic communities, as a disparate collection of vulnerable groups they often have limited meaningful social connectedness beyond these communities [9]. 
In the past decade community food gardens have increasingly been implemented as a localised urban intervention to improve access to low cost nutritious food, physical activity and community networks within urban populations in industrialised country settings [21-24]. Community food gardens contribute to the various needs of communities and are used not only for growing of nutritious foods, but also for such things as leisure, crime prevention, healing therapies, and ecological restoration [25]. The growing body of research and practice around community gardens highlights their roles in re-building localised urban food systems, contributing to food security and as part of the social mobilisation required for sustainable development [25-27]. Of particular note for the current research is the tendency for community gardens to include marginalised populations in social, collective endeavour where they can acquire skills, access nutritious and culturally relevant food and enjoy the physical and psychosocial benefits of tilling the earth [21-23,28,29].

In the context of the demonstrated effectiveness of community food gardening to promote community connectedness, this study explored how involvement in a community food garden supports African humanitarian migrant connectedness with their new country. Given the exploratory nature of the research, a qualitative approach was adopted with the study framed as a single critical case study [30,31] conducted on the community food garden sited on the grounds of a University campus in the City of Logan, Australia. A case study approach was adopted as a recognised strategy to develop understanding and explanations within social science research [32].

\section{Methods}

\subsection{Study Setting and Population}

Logan City in south-east Queensland (Figure 1) has an estimated resident population of 300,667 as of 30 June 2013, with $31 \%$ of the population residing in the most disadvantaged quintile [33]. It is a growing city that hosts an increasing diversity of cultures. It is a favoured settlement area for migrants due to its close proximity to Brisbane city and the Gold Coast together with the area's relatively affordable housing and established services and community support networks. Between 2006 and 2012, as a designated refugee settlement zone, almost 900 refugees were resettled in Logan City. Of all local government areas in Australia, Logan is ranked 8th for receiving the most number of humanitarian migrants [34]. There are several well established non-government organisations in Logan that provide a range of settlement, employment and training services to support the social, health and economic needs of humanitarian migrants. It was through links with these organisations that the need for access to land for growing traditional food crops was identified.

The Logan campus-based community food garden was established in 2006 with 45 individual plots each approximately $20 \mathrm{~m}^{2}$ together with a propagation area, shipping container for equipment and tool storage, several shaded communal areas, basic kitchen facilities and toilets. A map of the garden is presented as Figure 2. The figure shows the 45 individual plots with the important communal areas identified. The garden site is relatively flat with very poor soil quality. There is unlimited access to water from an adjacent lake through a dedicated water pump with underground pipes to taps positioned at strategic locations in the garden. Basic gardening resources are provided free of charge to the gardeners including wheel barrows, shovels, hoes, whipper snipper and lawn mower and soil 
conditioning products (e.g., gypsum, mulch). These resources have been funded through small grants and funds made available through the university, government departments and community organisations.

Figure 1. Location of Logan City in South-east Queensland, Australia [35] (Copyright permission was received from the Logan City Council Graphic Designer).

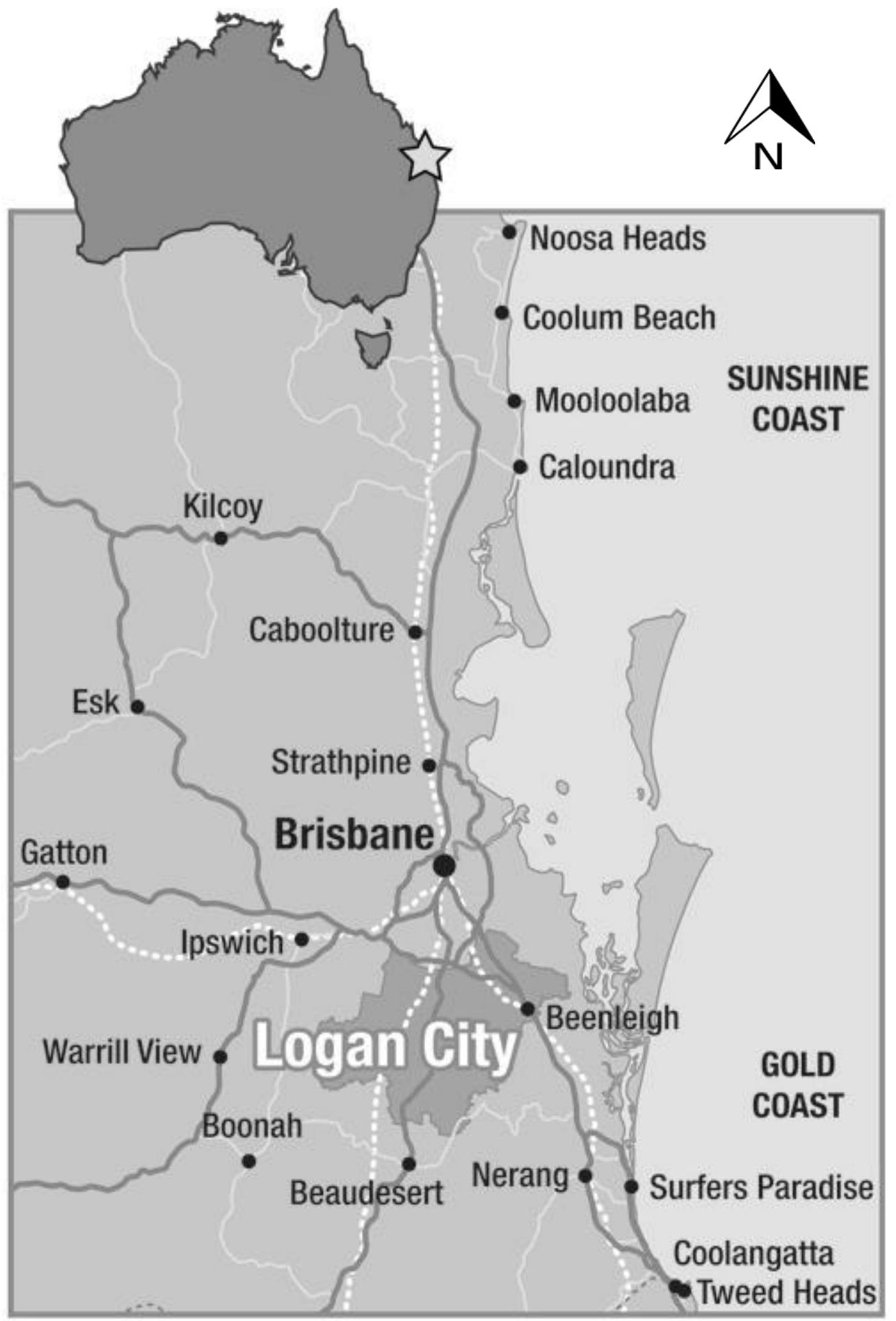


Figure 2. Logan Campus Based Community Food Garden Map.

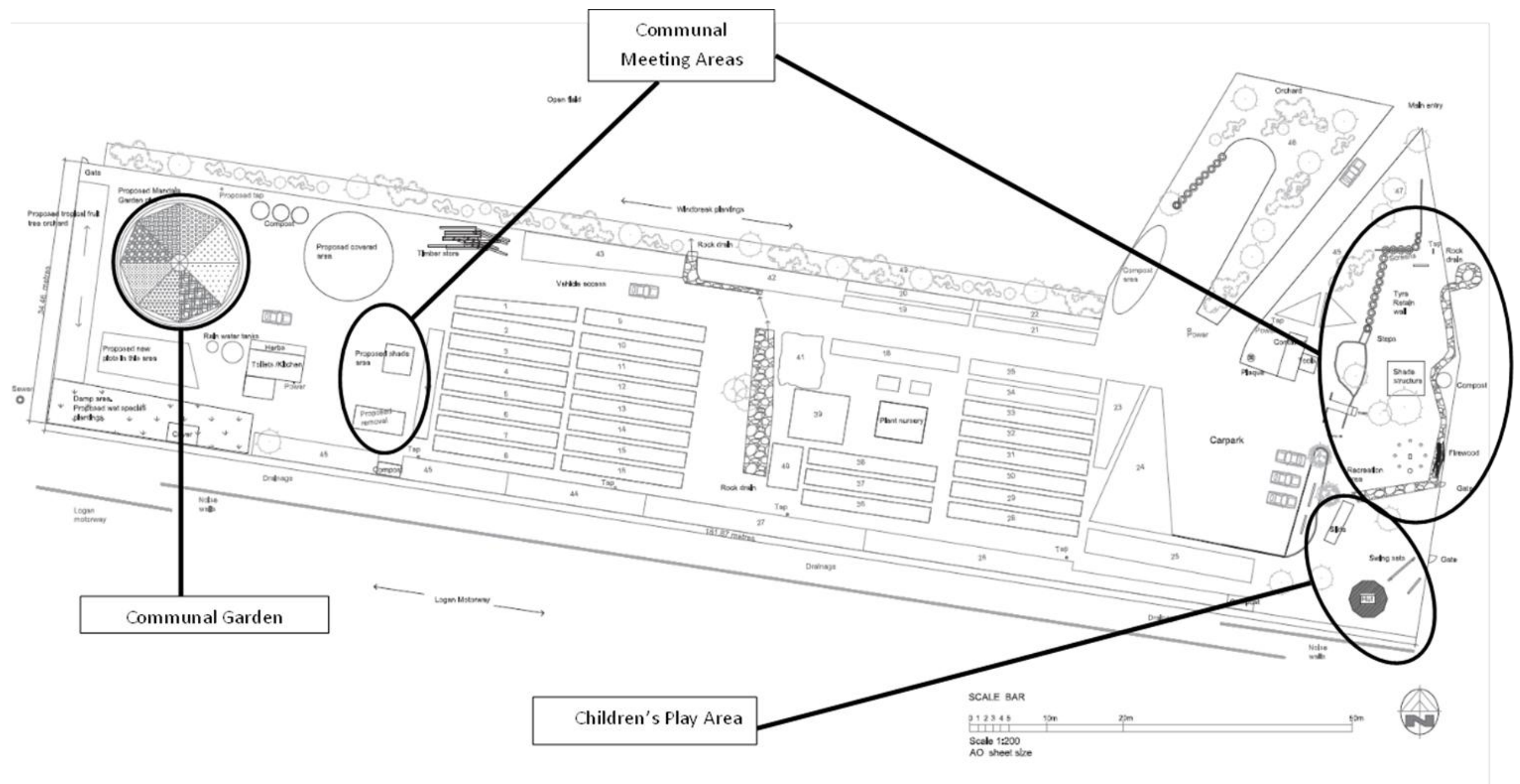


The garden has nearly 100 African humanitarian migrants from countries including Congo, Burundi, Somalia and Sudan. All are of lower socio-economic status with most being unemployed and undertaking settlement related classes for training in English language, life and employment skills. Consistent with the profile of the African humanitarian migrants to Australia, most of the gardeners are women with large families of up to seven or eight children. The gardeners work on their individual plots using their own and provided resources to prepare the plots then plant, tend and harvest crops including traditional foods such as cassava and maize and local foods such as pumpkins, bananas, tomatoes and strawberries. In the growing season, gardeners will visit the plot up to four or five times a week to water and tend their crops. As part of the community garden, gardeners, family, friends and others interested in food gardening and traditional foods are involved in the communal spaces for garden based events such as barbeques, meetings and information sessions around food gardening and nutrition.

Members of the local African refugee communities participated in the building of the garden with those interested being assigned plots. There is a waiting list for plots. This food garden has the highest refugee involvement of any community garden in Queensland, with 35 families working individual plots. It has been recognised nationally by the Refugee Council of Australia as one of 29 initiatives demonstrating best practice in settlement, self-sufficiency and participation in the community of newly-arrived humanitarian entrants. It has also been identified as an "important potential gathering place and opportunity for intercultural activity" in the 2006 Logan City Case Study Report developed for the international Intercultural City project.

\subsection{Data Collection and Analysis}

For the present study, semi-structured interviews were conducted, guided by an interview protocol comprising seed questions around participation in the garden. Semi structured interviews are a prominent and widely used data collection strategy in qualitative research and well suited to the purpose and nature of the research being undertaken [36,37]. Interviews were conducted with 12 purposively sampled individual gardeners who were recently settled African humanitarian migrants. Interviews were conducted as a conversation in the Garden setting as a familiar and comfortable location for the participants, recorded and transcribed verbatim. Questions were open ended, short and used easy to understand English to maximise accessibility and to encourage participants to share their views and experience of the garden. Interviews commenced with informed consent, included a couple of warm up questions about the participant's garden plot and then progressed through three seed questions:

1. Why did you join the garden?

2. Why do you come to the garden?

3. Why is being part of the garden important for you?

Thematic analysis of the transcripts first involved deconstructing participant responses by identifying and grouping key words or phrases throughout the dataset. These groupings together with a copy of the raw data were then shared with a second researcher to conduct a second round of analysis. Once completed, the two coders discussed the findings, clustered the data and named the three themes [38].

Ethics approval for the research was granted through a University Human Research Ethics Committee. 


\section{Results and Discussion}

The thematic analysis of the data from the participant interviews revealed three themes: Land Tenure; Re-connecting with Agri-Culture; and Community Belonging.

\subsection{Theme 1: Land Tenure}

The theme Land Tenure relates to the refugees having secure access to land (albeit small in size with individual plots being approximately $20 \mathrm{~m}^{2}$ ) they can legitimately farm. The following comments are indicative of this concept:

In Africa it is the citizens who have gardens. The foreigners do not have gardens. Now I have a garden, I feel like a citizen. (Gardener F)

This quote identifies the perceived link between plot tenure and participation in food gardening with becoming a citizen. It highlights the symbolism and connection with land and place that the garden provides for the migrants. At a more individual level, the next two quotes identify how food gardening is central to the gardeners' identity and sense of self:

When she digs her own farm and grows the way she knows, then she will eat what she knows.

(Gardener B).

While this quote is more abstract, it relates to using knowledge and skills from the gardener's past to produce crops that are familiar and of comfort. The next quote identifies the link between where the migrant has come from and their new beginnings facilitated by the secure access to land, in particular the opportunity to plant and grow crops, that the garden has offered:

He is relieved to have a land here to dig. He believes it was very important for an African person, if they didn't go to school, which majority didn't, they had to be a farmer.

So the closeness was very good, the bond between the human and the soil was of great importance. ... This is the only place here for him to dig so that is why it is important for him. (Gardener D).

Newly arrived humanitarian migrants are invariably housed in rental properties and this means they have no access to land to grow crops and connect with the Earth. Accordingly, access to a physical space that provides the place within which to engage in familiar activities becomes a significant milestone in their transition to their new country of residence $[39,40]$. Hence, the reference in the first quote to being a citizen. This theme is supported by previous research that has identified the role gardening plays in providing security and developing and maintaining a sense of self and belonging through biographical continuity across time and place between past and present experiences [41].

\subsection{Theme 2: Re-Connecting with Agri-Culture}

The theme Re-connecting with Agri-Culture recognises that many African humanitarian migrants have their origins in farming communities or have been involved in small scale food gardens to supplement food available either in their home country or refugee camps [42]. It is part of their being or culture and this is represented in the highlighting of this link by joining agriculture with culture as 
agri-culture. For these migrants, participation in a community food garden represents the familiar and purposeful activity of growing and harvesting crops, as suggested by the following comments by gardeners:

Both my parents were farmers. It's knowledge and skills passed down through the generations. I have just been given a plot and am doing everything according to my knowledge and talent basically. I plant them the way I know. (Gardener B)

This quote shows how participating in the garden offers a place for the migrant to practice their skills and knowledge - to re-connect with and celebrate their family and community background. The following quote shows how growing and harvesting crops offers the opportunity for achievement and feelings of happiness and success:

Remember when the maize grew, that was huge. That was amazing, it was like we had all this stuff. (Gardener G)

Together these two quotes identify how providing opportunity to apply knowledge and skills from the past can offer a means for migrants to feel more comfortable and capable in their new country of residence. Morgan and Ziglio [43] have described an assets based model of facilitating refugee settlement that views refugees as resourceful people who, with some assistance to adapt to the host culture, are able to address their own issues to achieve wellbeing and self-reliance. One gardener commented:

If you're a farmer, it covers the whole part of your life, in terms of exercising and in terms of your whole wellbeing. It is very important for me to be in the garden for my whole total wellbeing. (Gardener E)

This powerful quote summarises how being in the community food garden is important to the "whole total wellbeing" of the gardeners. As such, being in the garden provides migrants the place to practice the skills and life experiences they bring from their country of origin that can be harnessed to assist adaptation to their new context. The freedom to express one's cultural identity is integral to adapting to new surroundings. Community food gardens offer a place where the skills and life experiences of this population can be practiced and valued [44]. As such, the theme of Re-connecting with Agri-Culture specifically recognises the potential of community gardening to connect the migrant's life experience of agriculture with culture and their transitioning to life in a new country. This finding is consistent with research on community gardens that has demonstrated how participation in a garden offers individuals opportunity to practice and share their knowledge and skills with like-minded others [45].

\subsection{Theme 3: Community Belonging}

The theme Community Belonging relates to the role community gardens can play in building relationships and facilitating integration into the society. There is a variety of contexts for the concept of connectedness, though the use of the term in relation to group-level phenomena, such as a sense of caring/cohesion in community settings seems to predominate [46]. Connectedness is associated with positive behavioural, social and mental health outcomes [47]. A sense of belonging, including trust and mutual reciprocity (i.e., social capital [48]), on an individual level, promotes psychological well-being 
and at a broader level, promotes the social well-being of communities [48-50]. Participants consistently suggested involvement in the garden provided opportunity to build connections with others both within and beyond the garden through common interests in produce and farming.

She says when the produce are good it makes her happy because everything is good and she can share with other people. She relates better with people when she has good products and good produce. She feels good about it. (Gardener B)

Like last year, I grow maize and peanut in the garden and cassava, so I give it to my friends. It's a good thing to give it because if I have something they need I can give and if they have something I need, they can give to me also. (Gardener A)

These two quotes orient on how participation in the garden provides the individual gardener with produce they can share with others including family, friends and community. This is significant for the gardeners as often traditional crops such as maize can be expensive or difficult to source. As such, the sharing of produce with other community members beyond the garden offers the refugees a way to build their personal status within their local community and with other communities. This is significant in building their social connections and social capital. At a broader level, the following quotes show how participation in the community garden offers gardeners a sense of belonging to a community of life-minded individuals. These quotes identify the building of mutual reciprocity among the gardeners as they must work together and rely on each other to achieve their garden ambitions:

It brings a lot of, not only satisfaction but relief, sense of belonging and you feel people understand you, you feel people... you're part of that community that you're in. (Gardener A)

In the garden there, we work together, yeah .Get things done. Is good because we need to know each other and work together or things won't finish. (Gardener D)

The above comments highlight the gardeners' greater sense of belonging and connectedness through the sharing of produce with other community members, and through working collaboratively with other gardeners. As such, participation in food gardens facilitates processes of inclusion to overcome cultural, social and economic barriers commonly experienced by humanitarian migrants [51]. Much of the research on community gardens has recognised the capacity of gardens to build community and sense of belonging among diverse and often disparate groups through providing safe spaces for shared interests in gardening and associated matters such as land care, sustainable food systems and sustainability [27].

\subsection{Broader Significance of Findings}

The potential for production of culturally appropriate foods in this and other community gardens should not be overlooked, since it has important implications for food security. Access to food is an important determinant of diet and subsequent health outcomes [52-56]. Marginalised and disadvantaged communities and individuals, including refugees [14,57], often reside in so called "food deserts" [58] (i.e., residential areas with poor access to healthy food due to geography, in-store choice or affordability [59,60]). Although the designation of "food desert" often reflects poor access to food per se, rather than culturally appropriate food, dietary acculturation and its consequences are likely to 
be exacerbated by compromised access to culturally appropriate foods [57,14,61,62]. Community gardens are well documented for their ability to positively affect food choice by enhancing knowledge and self-efficacy in relation to production and preparation of vegetables and fruits $[21,22,28,63,64]$. The strong element of connectedness associated with gardening participation observed in this study implies a pathway for enhanced engagement with community gardens and other community-based health promotion settings. Community gardening presents an opportunity to enhance access to culturally appropriate food, and thus influence food choice $[65,66]$.

Wills and colleagues [67] have noted that community gardens may be more about community than gardening. The perceived benefits of community gardening reported in this study concur with this and revealed a strong desire for refugees to connect to their new country. A qualitative analysis of community garden participants by Kingsley and Townsend [68] showed that community gardens generated a perception of social connectedness amongst urban community members. Thus, although a primary aim of community gardening is to enhance food security, the present study showed that participation may also have flow-on effects on perceived connectedness for refugees.

Community-based public health intervention programs are continually challenged to engage difficult to reach at-risk populations. This single case study suggests that community gardening participation by African refugee families supports social connectedness. Given the single case design of the present study, further research perhaps in the guise of additional case studies of food gardens or other interventions engaging African refugees is needed to increase confidence in the generalizability of the study's findings. Once understood, these factors have potential to enhance engagement by this vulnerable group in other types of health promotion programs.

\section{Conclusions}

In summary, the concept validity of community gardens as culturally and socially relevant place-based interventions for vulnerable African refugee groups is supported by the reflections of garden participants in the present study. Specifically, community garden participation generates connectedness with their new country through the allocation of tenure of physical space for garden participants; by supporting a reconnection with the purposeful and familiar activity of growing food crops and by promoting a sense of belonging. Integrated within this is the contribution to food security through enhanced access to culturally appropriate foods in an environment that values and builds upon their social and cultural assets. As such, for African humanitarian migrants, participation in a community food garden offers a tangible means to build community connections and connect with their new country.

\section{Acknowledgments}

The authors thank the gardeners who so willingly gave of their time to be interviewed and show off their community food garden. 


\section{Author Contributions}

The authors contributed equally to the work. Fiona Rowe Minniss, Neil Harris and Shawn Somerset planned the research, Fiona Rowe Minniss managed the field work including data collection, Neil Harris and Shawn Somerset undertook the data analysis and preparation of the paper.

\section{Conflicts of Interest}

The authors declare no conflict of interest.

\section{References}

1. Popkin, B.M. Dynamics of the nutrition transition and its implications for the developing world. Forum Nutr. 2003, 56, 262-264.

2. Misra, A.; Ganda, O.P. Migration and its impact on adiposity and type 2 diabetes. Nutrition 2007, 23, 696-708.

3. Biddle, N.; Kennedy, S.; McDonald, J.T. Health assimilation patterns amongst Australian immigrants. Econ. Rec. 2007, 83, 16-30.

4. Sevoyan, A.; Hugo, G. Exploring Migrant Health in Australia. In Proceedings of the IUSSP XXVII International Population Conference, Busan, Korea, 26-31 August 2013.

5. Murray, S.B.; Skull, S.A. Hurdles to health: Immigrant and refugee health care in Australia. Aust. Health Rev. 2004, 29, 25-29.

6. Feldman, R. Primary health care for refugees and asylum seekers: A review of the literature and a framework for services. Public Health 2006, 120, 809-816.

7. Maffla, C. Health in the age of migration: Migration and health in the EU. Community Pract. 2008, 81, 32-35.

8. Tiong, A.C.D.; Patel, M.S.; Gardiner, J.; Ryan, R.; Linton, K.S.; Walker, K.A.; Scopel, J.; Biggs, B.-A. Health Issues in newly arrived African refugees attending general practice clinics in Melbourne. Med. J. Aust. 2006, 185, 602-606.

9. NSW Health. Refugees from Africa. Available online: http://www.swslhd.nsw.gov.au/refugee/ pdf/Resource/FactSheet/FactSheet_06.pdf (accessed on 2 July 2014).

10. Refugee Week. Background Information on Refugees and Asylum Seekers. Available online: http://www.refugeeweek.org.au/resources/background.php (accessed on 30 July 2014).

11. Jakubowicz, A. Australia's Migration Policies: African Dimensions. Available online: https://www.humanrights.gov.au/sites/default/files/content/africanaus/papers/africanaus_paper_ jakubowicz.pdf (accessed on 30 July 2014).

12. Australian Bureau of Statistics. 3412.0-Migration, Australia, 2009-2010. Available online: http://www.abs.gov.au/ausstats/abs@.nsf/0/52F24D6A97BC0A67CA2578B0001197B8?open document (accessed on 30 July 2014).

13. Hart, E.W. Settlement Geography of African Refugee Communities in Southeast Queensland: An Analysis of Residential Distribution and Secondary Migration. Available online: http://eprints.qut.edu.au/38622/1/Elizabeth_Harte_Thesis.pdf (accessed on 30 July 2014). 
14. Sheikh-Mohammed, M.; Macintyre, C.R.; Wood, N.J.; Leask, J.; Isaacs, D. Barriers to access to health care for newly resettled sub-Saharan refugees in Australia. Med. J. Aust. 2006,185, 594-597.

15. Renzaho, A.M.; Gibbons, C.; Swinburn, B.; Jolley, D.; Burns, C. Obesity and undernutrition in Sub-Saharan African immigrant and refugee children in Victoria, Australia. Asia Pac. J. Clin. Nutr. 2006, 15, 482-490.

16. Hadley, C.; Sellen, S. Food security and child hunger among recently resettled Liberian refugees and asylum seekers: A pilot study. J. Immigr. Minor. Health 2006, 8, 369-375.

17. Burns, C. Effect of migration on food habits of Somali women living as refugees in Australia. Ecol. Food Nutr. 2004, 43, 213-229.

18. Crane, N.T.; Green, N.R. Food habits and food preferences of Vietnamese refugees living in northern Florida. J. Amer. Diet. Assn. 1980, 76, 591-593.

19. Renzaho, A.M. Post-Migration food habits of Sub-Saharan African. Nutr. Diet. 2006, 63, 91-102.

20. Flanagan, S.M.; Hancock, B. "Reaching the hard to reach"-Lessons learned from the VCS (Voluntary and Community Sector). A qualitative study. BMC Health Serv. Res. 2010, 10, doi:10.1186/1472-6963-10-92.

21. Armstrong, D. A survey of community gardens in upstate New York: Implications for health promotion and community development. Health Place 2000, 6, 319-327.

22. Baker, L.E. Tending cultural landscapes and food citizenship in Toronto's community gardens. Geogr. Rev. 2004, 94, 305-325.

23. Myers, M.S. Empowerment and community building through a gardening project. Psychiatr. Rehabilitat. J. 1998, 22, 181-183.

24. Wakefield, S.; Yeudall, F.; Taron, C.; Reynolds, J.; Skinner, A. Growing urban health: Community gardening in south-east Toronto. Health Promot. Int. 2007, 22, 92-101.

25. Ferris, J.; Norman, C.; Sempik, J. People, land and sustainability: Community gardens and the social dimension of sustainable development. Soc. Policy Admin. 2001, 35, 559-568.

26. Hamm, M.W.; Baron, M. Developing an integrated, sustainable urban food system: The case of New Jersey, United States. In For Hunger-Proof Cities Sustainable Urban Food Systems; Koc, M., MacRae, R., Mougeot, L.J.A., Welsh, J., Eds.; IDRC: Ottawa, ON, Canada, 1999.

27. Allen, P. Reweaving the food security safety net: Mediating entitlement and entrepreneurship. Agric. Human Values 1999, 16, 117-129.

28. Austin, E.N.; Johnston, Y.A.; Morgan, L.L. Community gardening in a senior center: A therapeutic intervention to improve the health of older adults. Ther. Recreat. J. 2006, 40, 48-56.

29. Schmelzkopf, K. Urban community gardens as contested space. Geogr. Rev. 1996, 85, 364-381.

30. Neuman, W.L. Basics of Social Research. Qualitative and Quantitative Approaches, 3rd ed.; Pearson: Boston, MA, USA, 2012.

31. Yin, R.K. Case study research. In Design and Methods, 3rd ed.; Sage Publications: Thousand Oaks, CA, USA, 2003; Volume 5.

32. George, A.L.; Bennett, A. Case Studies and Theory Development in the Social Sciences; MIT Press: London, UK, 2005.

33. Queensland Government, Queensland Treasury and Trade. Queensland Regional Profiles: Resident Profile for Logan City Local Government Area. Available online: http://statistics.oesr.qld.gov.au/qld-regional-profiles (accessed on 30 June 2014). 
34. Logan City Council. Logan City Cultural Diversity Strategy 2013-2016. Available online: http://www.logan.qld.gov.au/_data/assets/pdf_file/0008/111104/Cultural-Diversity-Strategy-20132016-Draft-for-Public-Consultation.pdf (accessed on 30 June 2014).

35. Logan City Council. Living in Logan: Maps. Available online: http://www.logan.qld.gov.au/aboutlogan/living-in-logan/maps (accessed on 10 August 2014).

36. Liamputtong, P.; Ezzy, D. Qualitative Research Methods, 2nd ed.; Oxford University Press: South Melbourne, Australia, 2005.

37. Baxter, J.; Eyles, J. Evaluating qualitative research in social geography: Establishing "rigour" in interview analysis. Trans. Inst. Br. Geogr. 1997, 22, 505-525.

38. Matthew, B.M.; Huberman, A.M. Qualitative Data Analysis: An Expanded Sourcebook; Sage: Thousand Oaks, CA, USA, 1994.

39. Dyck, I.; Dossa, P. Place, health and home: Gender and migration in the constitution of healthy space. Health Place 2007, 13, 691-701.

40. Sampson, R.; Gifford, S.M. Place-making, settlement and well-being: The therapeutic landscapes of recently arrived youth with refugee backgrounds. Health Place 2010, 16, 116-131.

41. Li, W.W.; Hodgetts, D.; Ho, E. Gardens, transitions and identity reconstruction among older Chinese immigrants to New Zealand. J. Health Psychol. 2010, 15, 786-796.

42. Robertson, A.; James, W. War in the former Yugoslavia: Coping with nutritional issues. In Essentials of Human Nutrition; Mann, J.I., Truswell, A.S.T., Eds.; Oxford University Press: New York, NY, USA, 1998; pp. 557-574.

43. Morgan, A.; Ziglio, E. Revitalising the evidence base for public health: An assets model. Promot. Educ. 2007, 2, S17-S22.

44. ACT Government, Environment and Planning. A Study of the Demand for Community Gardens and Their Benefits for the ACT Community. Available online: http://www.actpla.act.gov.au/ tools_resources/research_based_planning_for_a_better_city/demand_for_community_gardens_and_ their_benefits (accessed on 2 July 2014).

45. Christensen, P. Farming the city. Local-Glob. Identity Secur. Community 2007, 4, 34-39.

46. Jordans, M.; Tol, W.; Kimproe, I.; Jong, D.J. Systematic review of evidence and treatment approaches: Psychosocial and mental health care for children in war. Child. Adolesc. Ment. Health 2009, 14, 2-14.

47. Resnick, M.D.; Bearman, P.S.; Blum, R.W.; Bauman, K.E.; Harris, K.M.; Jones, J.; Tabor, J.; Beuhring, T.; Sieving, R.E.; Shew, M.; et al. Protecting adolescents from harm. Findings from the national longitudinal study on adolescent health. JAMA 1997, 278, 823-832.

48. Kawachi, I.; Berkman, L.F. Social ties and mental health. J. Urban Health 2001, 78, 458-467.

49. Marmot, M. Social determinants of health: From observation to policy. Med. J. Aust. 2000, 172, 379-382.

50. Onyx, J.; Leonard, R. The conversion of social capital into community development: An intervention in Australia's outback. Int. J. Urban Reg. Res. 2010, 34, 381-397.

51. Williams, E.; Harris, N. Understanding the nutrition information needs of migrant communities: The needs of African and Pacific Islander communities of Logan, Queensland. Public Health Nutr. 2011, 14, 989-994. 
52. Timperio, A.; Ball, K.; Roberts, R.; Campbell, K.; Andrianopoulos, N.; Crawford, D. Children's fruit and vegetable intake: Associations with the neighbourhood food environment. Prev. Med. 2008, 46, 331-335.

53. Moore, L.V.; Roux, A.V.D.; Brines, S. Comparing perception-based and geographic information system (GIS)-based characterizations of the local food environment. J. Urban Health. 2008, 85, 206-216.

54. Larson, N.I.; Story, M.T.; Nelson, M.C. Neighbourhood environments: Disparities in access to healthy food in the U.S. Amer. J. Prev. Med. 2009, 36, 74-81.

55. Spence, J.C.; Cutumisu, N.; Edwards, J.; Raine, K.D. Smoyer-Tomic K. Relation between local food environments and obesity among adults. BMC Public Health. 2009, 9, 192-197.

56. Rose, D. Richards R. Food store access and household fruit and vegetable use among participants of the U.S. food stamp program. Public Health Nutr. 2004, 7, 1081-1088.

57. Grondin, D. Well-managed migrants' health benefits all. Bull. WHO 2004, 82. Available online: http://www.who.int/bulletin/volumes/82/8/editorial20804html/en/ (accessed on 25 August 2014).

58. Larsen, K.; Gilliland, J. Mapping the evolution of "food deserts" in a Canadian city: Supermarket accessibility in London, Ontario, 1961-2005. Int. J. Health Demogr. 2008, 7, 16-33.

59. Beaulac, J.; Kristjansson, E.; Cummins, S. A systematic review of food deserts, 1966-2007. Prev. Chronic Dis. 2009, 6. Available online: http://www.cdc.gov/pcd/issues/2009/jul/08_0163.htm (accessed on 25 August 2014).

60. Bodor, J.N.; Rose, D.; Farley, T.A.; Swalm, C.; Scott, S.K. Neighbourhood fruit and vegetable availability and consumption: The role of small food stores in an urban environment. Public Health Nutr. 2007, 11, 412-420.

61. Muecke, M.A. New paradigms for refugee health problems. Soc. Sci. Med. 1992, 35, 515-523.

62. Gushulak, B.D.; MacPherson, D.W. The basic principles of migration health: Population mobility and gaps in disease prevalence. Emerg. Themes Epidemiol. 2006, 3, 3-14.

63. Somerset, S.; Ball, R.; Flett, M.; Geissman, R. School-based community gardens: Re-establishing healthy relationships with food. J. Home Econ. Inst. Aust. 2005, 12, 25-33.

64. Somerset, S.; Markwell, K. Impact of a school-based food garden on attitudes and identification skills regarding vegetables and fruit: A 12-month intervention trial. Public Health Nutr. 2008, 12, 214-221.

65. Saldivar-Tanaka, L.; Krasny, M.E. Culturing community development, neighbourhood open-space, and civic agriculture: The case of Latino community gardens in New York city. Agric. Hum. Values 2004, 21, 399-412.

66. Cummings, D.; Rowe, F.; Harris, N.; Somerset, S. Quality of Life and Community Gardens: African Refugees and the Griffith University Community Food Garden. In Proceedings of Population Health Congress, Brisbane, Australia, 6-9 July 2008; p. 11.

67. Wills, J.; Chinemana, F.; Rudolph, M. Growing or connecting? An urban food garden in Johannesburg. Health Promot. Int. 2010, 25, 33-41. 
68. Kingsley, J.Y.; Townsend, M. "Dig In" to social capital: Community gardens as mechanisms for growing urban social connectedness. Urban Policy Res. 2006, 24, 525-537.

(C) 2014 by the authors; licensee MDPI, Basel, Switzerland. This article is an open access article distributed under the terms and conditions of the Creative Commons Attribution license (http://creativecommons.org/licenses/by/3.0/). 